\title{
1 Exploring the phylogeny of rosids with a five-locus supermatrix from GenBank
}

2 Miao Sun $^{1,2,3 *}$, Ryan A. Folk ${ }^{4}$, Matthew A. Gitzendanner ${ }^{2,5}$, Stephen A. Smith ${ }^{6}$, Charlotte

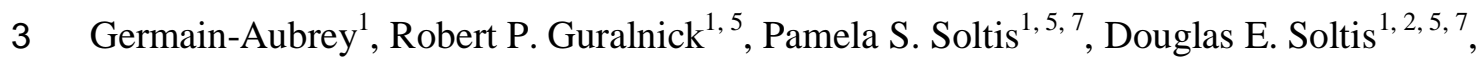

4 Zhiduan Chen $^{3 *}$

5

6 1. Florida Museum of Natural History, University of Florida, Gainesville, FL 32611, USA

7 2. Department of Biology, University of Florida, Gainesville, FL 32611, USA

8 3. State Key Laboratory of Systematic and Evolutionary Botany, Institute of Botany, the

9 Chinese Academy of Sciences, Beijing 100093, China

10 4. Department of Biological Sciences, Mississippi State University, Mississippi State, MS

11397627, USA

12 5. Biodiversity Institute, University of Florida, Gainesville, FL 32611, USA

13 6. Department of Ecology and Evolutionary Biology, University of Michigan, Ann Arbor, MI

14 48109, USA

15 7. Genetics Institute, University of Florida, Gainesville, FL 32608, USA

16

17 *Corresponding authors:

18 Miao Sun: cactusresponsible@gmail.com

19 Zhiduan Chen: zhiduan@ibcas.ac.cn

20 


\section{Abstract: 217 \\ 22 Text: total words: 3553 \\ 23 Introduction: 720}

24 Materials and Methods: 932

25 Results: 1247

26 Discussion: 724

27 Acknowledgements: 96

28 Author contributions: 62

29 Figures: 3

30 Colored: 3

31 Tables: 2

32 Supporting information:

33 Supplementary figure: 1

34 Supplementary tables: 3

35

36 Running headline: Phylogeny and dating of rosids

37 


\section{Abstract}

39 Current advances in sequencing technology have greatly increased the availability of

40 sequence data from public genetic databases. With data from GenBank, we assemble and

41 phylogenetically investigate a 19,740-taxon, five-locus supermatrix (i.e., atpB, $r b c L$, matK,

42 matR, and ITS) for rosids, a large clade containing over 90,000 species, or approximately a

43 quarter of all angiosperms (assuming an estimate of 400,000 angiosperm species). The

44 topology and divergence times of the five-locus tree generally agree with previous estimates

45 of rosid phylogeny, and we recover greater resolution and support in several areas along the

46 rosid backbone, but with a few significant differences (e.g., the placement of the COM clade,

47 as well as Myrtales, Vitales, and Zygophyllales). Our five-locus phylogeny is the most

48 comprehensive DNA data set yet compiled for the rosid clade. Yet, even with 19,740 species,

49 current sampling represents only $16-22 \%$ of all rosids, and we also find evidence of strong

50 phylogenetic bias in the accumulation of GenBank data, highlighting continued challenges

51 for species coverage. These limitations also exist in other major angiosperm clades (e.g.,

52 asterids, monocots) as well as other large, understudied branches of the Tree of Life,

53 highlighting the need for broader molecular sampling. Nevertheless, the phylogeny presented

54 here improves upon sampling by more than two-fold and will be an important resource for

55 macroevolutionary studies of this pivotal clade.

56 Keywords: Mega-phylogeny, rosids, dating, GenBank, sampling 


\section{$58 \quad$ I. Introduction}

59 Given their size, rosids (Rosidae; Cantino et al., 2007; Wang et al., 2009; APG IV,

60 2016) have great potential for understanding the evolution and diversification of

61 angiosperms. A clade of 90,000-120,000 species (estimated from the Open Tree of Life and

62 Open Tree Taxonomy database (OTT); Hinchliff et al., 2015), the rosid clade represents more

63 than a quarter of all angiosperms (based on an estimated 400,000 species of angiosperms;

64 Govaerts, 2001). Rosids comprise two large subclades, fabids (i.e., eurosids I, Fabidae) and

65 malvids (i.e., eurosids II, Malvidae) and are further divided into 17 orders and 135 families

66 (APG IV, 2016). The clade originated in the Early to Late Cretaceous (115 to 93 Million

67 years ago, Myr), followed by rapid diversification yielding the crown groups of fabids (112 to

$6891 \mathrm{Myr}$ ) and malvids (109 to 83 Myr; Wang et al., 2009; Bell et al., 2010; Magallón et al.,

69 2015). The rosid clade diversified rapidly to form the two major lineages in perhaps as little as 4 to 5 million years (Wang et al., 2009; Bell et al., 2010).

Most rosid families have high species diversity in the tropics, but many extend from

the tropics to subtropical and temperate areas (e.g., Wang et al., 2009; Soltis et al., 2010).

Most ecologically dominant forest trees are found within the clade, as well as diverse aquatics, parasites, arctic, alpine, and desert lineages; the clade also exhibits tremendous diversity in chemistry, reproductive strategy, and life history (Magallón et al., 1999; Wang et al., 2009; Stevens, 2001 onwards). Unique ecological traits are prevalent in the rosids, including nodular association with nitrogen-fixing bacteria (Soltis et al., 1995; Li et al., 2015), chemical defense mechanisms including glucosinolate production in Brassicales (Rodman et al., 1998; Soltis et al., 2005; Edger et al., 2015), and independent origins of parasitism, sometimes associated with rampant horizontal gene transfer (e.g., Rafflesia; Davis \& Wurdack, 2004; Xi et al., 2012). Many important crops are rosids, including cotton and cacao (Malvaceae), hops (Cannabaceae), legumes (Fabaceae), rubber (Euphorbiaceae), and numerous vegetable and fruit crops (Brassicaceae, Caricaceae, Cucurbitaceae, Rosaceae,

84 Rutaceae, and Vitaceae). Some rosids have been selected as genetic models, including 85 Arabidopsis thaliana (Arabidopsis Genome Initiative, 2000), Brassica rapa (Wang et al., 86 2011), and various legumes (Sato et al., 2008; Schmutz et al., 2010, 2014; Varshney et al., 2012, 2013; Young et al., 2011).

The "rise of the rosids" yielded most angiosperm-dominated forests present today.

89 Many other lineages of life radiated in the shadow of these rosid-dominated forests (e.g., 90 ants: Moreau et al., 2006; Moreau \& Bell, 2013; beetles: Farrell, 1998; Wilf et al., 2000; 
91 amphibians: Roelants et al., 2007; mammals: Bininda-Emonds et al., 2007; fungi: Hibbett \&

92

Matheny, 2009; liverworts: Feldberg et al., 2014; ferns: Schneider et al., 2004; Watkins \& Cardelús, 2012). The initial rise of the rosids and subsequent repeated cycles of radiations within the rosid clade (Soltis \& Soltis, 2004; Soltis et al., 2004) have profoundly shaped much of current terrestrial biodiversity (Wang et al., 2009; Boyce et al., 2010).

Although rosids have long been the focus of phylogenetic research (e.g., Wang et al., 2009; Soltis et al., 2011; Zeng et al., 2017; and references therein), the enormous size of this clade has thus far precluded achieving the sampling required for macroevolutionary inferences (Ricklefs, 2007; Smith et al., 2011; Thomas et al., 2013; Folk et al., 2018). Hence, a robust, time-calibrated phylogeny with large-scale species-level sampling is needed for future diversity studies. Additionally, the rosid clade also provides an opportunity to evaluate the implications of taxon and gene sampling. Using data from GenBank, we constructed a 5locus phylogenetic tree having more than twice the taxon sampling used in earlier studies (e.g., the 4-locus study of Sun et al., 2016) — and compared this tree to all rosid names in the OpenTree of Life (Hinchliff et al., 2015) to quantify bias in DNA sampling across the clade. We hypothesized that (1) taxon sampling remains highly biased across the large rosid clade, and that (2) the use of more genes and increased taxon sampling impacts phylogenetic resolution and divergence time estimation. We tested these hypotheses via a series of comparisons across two trees: a previously published 4-locus, 8,855-taxon supermatrix (Sun et al, 2016) and the more densely sampled 5-locus, 19,740-taxon supermatrix generated here. We then quantified patterns of taxon sampling bias, phylogenetic resolution, and time calibration.

\section{Materials and Methods}

\section{Data mining, alignment, and phylogeny reconstruction}

We mined GenBank (Release 214: June 15, 2016) for the chloroplast genes atpB, $m a t K$, and $r b c L$, the mitochondrial gene matR, and the nuclear ribosomal ITS (including ITS1, 5.8S, and ITS-2 regions) using the PHyLogeny Assembly With Databases pipeline (PHLAWD, version 3.4a, https://github.com/blackrim/phlawd; Smith et al., 2009). These genes represent those most commonly used in phylogenetic studies of plants and therefore the most numerous loci for plants deposited in GenBank; they also represent all three plant genomes.

We employed PHLAWD data mining using three bait sequences of each target locus 
123 that represent the phylogenetic diversity of the rosid clade (Hinchliff \& Smith, 2014). The

124 quality of sequence data from the five sampled loci was investigated by calculating the best-

125 hit scores from BLAST and plotting the distribution of identity scores $([0,1])$ against

126 coverage scores $([0,1])$. Low-quality and outlier sequences were removed based on these

127 scores (see Results). For all resulting alignments, we (1) validated the species names

128 following The Plant List (TPL; http://www.theplantlist.org/), using the R package

129 Taxonstand v2.0 (Cayuela et al., 2012), and then (2) pruned all taxa with "subsp.", "var.",

130 "f.", "cf." and "aff." designations in taxon names. Names for orders and families follow APG

131 IV (2016), and those for major supra-ordinal clades follow Soltis et al. (2011) and Cantino et

132 al. (2007).

133 We curated the 5-locus data set iteratively by screening individual loci and

134 concatenated matrices (below) for rogue taxon behavior through manual inspection of initial

135 phylogenies for spurious taxon placement and through the RAxML dropsets algorithm

136 (Pattengale et al., 2010a; Sun et al., 2016; Smith \& Brown, 2018). The final 5-locus data set

137 contained 19,740 ingroup species (135 families and 17 orders) and 20,294 species, including

138 outgroup taxa (i.e., 554 outgroup species in 17 families and three orders) from Saxifragales,

139 Proteales, and Trochodendrales.

140 We also compared results from our 5-locus (atpB, $r b c L$, matK, matR, and ITS) data

141 set with those from a previously published 4-locus rosid data set comprising chloroplast and

142 mitochondrial loci (Sun et al., 2016; atpB, rbcL, matK, and matR). The 4-locus data set

143 contained 8,855 ingroup taxa (9,300 taxa including outgroups; i.e., 445 outgroup species

144 from the same three orders; Sun et al., 2016). Hereafter, all tree sampling statistics will only

145 concern the ingroup.

146 Taxon sampling analyses

147 To evaluate sampling gaps among all taxonomically recorded rosid species and the

148 species included in the 5-locus data set, we mapped the 19,740 validated rosid names in our

149 phylogeny against all rosid species present in OTT v3.0

150 (https://devtree.opentreeoflife.org/about/taxonomy-version/ott3.0; Hinchliff et al., 2015).

151 Generic names of this complete list were also manually curated via an online tool, Index

152 Nominum Genericorum (Farr \& Zijlstra, 1996 onwards), and then invalid, rejected (nom.

153 rej.), illegitimate, and synonymous generic names were all removed, as well as any taxon

154 names with "sp.”, "subsp.”, “var.”, “x”, “cf.” and "aff.”, or other non-species designations

155 (e.g., "spp.", “clone”, “environmental sample”, "group”). 
156 Additionally, to evaluate whether sampling in rosid DNA data from GenBank is

157 phylogenetically biased, we scored DNA data presence and absence by mapping our

158 phylogeny names to OpenTree (Smith \& Brown, 2018) and then executing a $\lambda$ test on this

159 "trait" under an equal rates model (R packge geiger V.2.0.6.2; Pennell et al., 2014).

160 Significance was assessed with a likelihood ratio test.

161 Phylogenetics

162 The edited and pruned alignments of each locus were concatenated into a single

163 supermatrix using FASconCAT v.1.0 (Kück \& Meusemann, 2010). We ran maximum

164 likelihood (ML) analyses for each individual locus alignment and for the concatenated

165 matrices using RAxML v.8.2.10 (Stamatakis, 2014) with 100 bootstrap (BS) replicates for

166 topology examination, under an unpartitioned GTRCAT model. For the 5-locus concatenated

167 matrix, the best ML tree was constructed with RAxML using the extended Majority Rule

168 Criterion (autoMRE) as a bootstrap stopping rule (Pattengale et al., 2010b; reached at 352

169 replicates). We visually examined potential topological conflicts by concatenating different

170 data sets and evaluating strongly supported differences among trees at the family level

171 inferred from the combined supermatrix and of each individual data set (i.e., ITS, matR, and

172 the plastid genes; see Results and Discussion). Trees were manipulated for display using

173 Newick utilities (Junier \& Zdobnov, 2010), Dendroscope 3 (Huson \& Scornavacca, 2012),

174 MEGA (Tamura et al., 2013), and iTOL v3.0 (Letunic \& Bork, 2016).

\section{Divergence Time Estimation}

176 Divergence time estimation was conducted using both the previously published 4-locus

177 (Sun et al., 2016) phylogeny and newly constructed 5-locus phylogeny. In total, 59

178 calibration points (covering 15/17 rosid orders) were used as time constraints, based on

179 validated fossils frequently used as calibration points in previous molecular dating studies

180 (Davis et al., 2005; Wang et al., 2009; Bell et al., 2010; Sauquet et al., 2012; Magallón et al.,

181 2015; Table S1). The root was constrained to a maximum age of $125 \mathrm{Myr}$ following Wang et

182 al. (2009). For both phylogenies, we used the penalized likelihood program treePL v.1.0

183 (Smith \& O'Meara, 2012) to generate a time-calibrated ultrametric tree. We initially

184 conducted random cross-validation procedures with three options ("randomcv", "thorough",

185 and "prime") to determine the best smoothing value and optimization parameters for both the

186 4-locus and 5-locus ML trees and then ran 200,000 annealing iterations (default = 5,000) for

187 divergence time estimation. 
To estimate variation in the timing of the rosid divergence, we also employed PATHd 8 v.1.0 (Britton et al., 2006) using the same 59 calibration points and root constraint as above.

\section{Results}

\section{Limitations in Taxon and Locus Sampling}

For the commonly sequenced locus ITS, PHLAWD initially recovered 42,890 rosid sequences; after removing sequences with non-species designations (cf. Materials and Methods), 39,735 sequences remained. Removal of sequences with low identity and coverage scores (coverage score $\leq 0.1$ and identity score $\leq 0.1$ were considered low quality) and further duplicate removal and non-ortholog cleaning, 15,100 sequences remained in the single locus matrix; however, only 13,157 sequences were retained in the final combined supermatrix for phylogeny reconstruction, due to two reasons: 1) some ITS sequences still exhibiting characteristics of rogue taxa identified by initial RAxML analyses in primary 5-locus supermatrix (Pattengale et al., 2010; Sun et al., 2016); and 2) in this combined matrix, some species have only one fragment of either ITS1, 5.8S, or ITS2, and the other four genes are not available; therefore, these short single ITS fragments were removed from the combined matrix to avoid introducing large amounts of missing data. Updating the remaining loci (atpB, rbcL, matK, and matR) with new GenBank data resulted in 1,257, 6,960, 8,489, and 721 sequences, respectively. The alignment lengths for $a t p B, r b c L$, matK, matR, and ITS were, respectively, 1,500,1,401, 1,815, 2,349, and $835 \mathrm{bp}$, with a concatenated length of $7,900 \mathrm{bp}$, and $70.55 \%$ missing data.

211 To better understand sampling patterns in our data sets, we matched our recovered 212 phylogenetic tips (species) with those in the Open Tree of Life taxonomic database (OTT 213 v3.0; Hinchliff et al., 2015), which includes rosid clades-e.g., Rutaceae, Francoaceae, and

214 Kirkiaceae-yet to be integrated into the Open Tree topology itself. We sampled 135 families 215 (100\% coverage of the rosid families recognized in APG IV, 2016), 3,070 genera (matching $21666.34 \%$ of OTT), and 19,740 species (matching 16.25\% of OTT). The unsampled genera and 217 species mainly reflect absence of DNA data (Fig. 1 and Tables 1, S2), but some are due to 218 taxonomic issues such as synonyms and invalid names. Among these mismatches are names 219 in our 5-gene tree unaccounted for in OTT, comprising 1,134 species (5.74\%) and 72 genera 
$220(2.35 \%)$. Total coverage and taxon representation compared with the rosids present in OTL

221

222

223

224

225

226

227

228

229

230

231

232

233

234

235

236

and OTT are summarized in Table 1, and Table S2, respectively (order and family

circumscription adjusted to comply with APG IV [2016]; marked with asterisks in Table S2).

Sampling coverage in our tree shows a strong phylogenetic bias ( $p$-value for $\lambda$ test, $p$

$\approx 0$; Fig. 1 and Tables 1, S2). Overall, larger orders (> 10,000 species, e.g., Rosales and Myrtales) tend to be more poorly sampled with $>90 \%$ of the species unsampled (Table 1).

Several large families (> 1,000 species) also have poor coverage; Polygalaceae, Rosaceae, Myrtaceae, Malvaceae, Rutaceae, and Phyllanthaceae have 3.14\% to $15.27 \%$ sampling (Table S2). Geraniales, Crossosomatales, Brassicales, Cucurbitales, and Huerteales have better sampling, yet no order or family exceeds $50 \%$ coverage of known species richness.

\section{Phylogenetic Analyses}

The topology of our 5-locus rosid tree (Fig. S1) generally agrees with that of the 4locus tree inferred in a previous GenBank mining effort (Sun et al., 2016), but provides greater resolution and support in several areas along the backbone (Fig. S1) as well as greatly improved species-level sampling. The median BS value of the 5-locus rosid tree is lower than that obtained in the 4-locus, 8,855-taxon rosid phylogeny (Fig. 2a), but within methodological expectations (see Discussion).

The topologies inferred from single locus partitions and the concatenated data set are generally consistent, with the exception of the following conflicting phylogenetic placements: (1) For the COM clade (Celastrales-Oxalidales-Malpighiales), we observed the same conflicting placements when trees from nuclear, plastid, and mitochondrial data are compared as observed in Sun et al. $(2015,2016)$. Nuclear and mtDNA data favor a placement of the COM clade with malvids, whereas plastid data indicate a placement with fabids. (2) The placement of Myrtales and Geraniales was unstable across locus partitions. In the chloroplast tree, Myrtales and Geraniales were sequential sisters to fabids with strong support, but in the matR tree and total evidence tree, Myrtales and Geraniales were sisters to the rest of the rosids (cf. Sun et al., 2015, 2016). The monophyly of Myrtales was not supported in the ITS tree. (3) The placement of Zygophyllales varied among locus partitions. In the matR tree, Zygophyllales were resolved as sister to malvids (cf. Sun et al., 2016; Zhao et al., 2016), a different result from the chloroplast and total evidence trees, where the clade was placed within fabids with low to moderate support. (4) The placement of Vitales with respect to the rest of the rosids and Saxifragales was unstable across analyses. In the matR and total evidence trees, the three groups were resolved as (rosids + Vitales) + Saxifragales (cf. Sun et 
253 al., 2016), a topology that has also been recovered in most studies (Soltis et al., 2007, 2011;

254 Worberg et al., 2007; Zhu et al., 2007; APG, 2009, 2016; Wang et al., 2009; Smith et al., 2010; Barniske et al., 2012; Ruhfel et al., 2014). Our chloroplast data set, by contrast, recovers the relationship among these three clades as rosids + (Saxifragales + Vitales), a result also seen previously (cf. Moore et al., 2010; Ruhfel et al., 2014; Zhang et al., 2012, 2016; Sun et al., 2016). (5) Non-monophyly of some families was occasionally seen within single-gene trees. Two families (Cannabaceae and Euphorbiaceae) are resolved as nonmonophyletic in the combined plastid tree, while they are recovered as monophyletic in the total evidence tree as expected; similarly, 12 families are non-monophyletic in the mat $R$ gene tree and 18 in the ITS tree (see Table S3).

The crown age of rosids is estimated as 117.93 Myr by treePL (89.80 Myr by PATHd8) using the 5-locus tree, and 122.62 Myr by treePL (104.20 Myr by PATHd8) for the 4-locus tree. The ages of other major rosid clades are reported in Table 2. Comparisons of crown ages obtained for all major rosid clades (17 orders and 135 families, sensu APG IV) are provided in Figs. $2 \mathrm{~b}$ and 3, covering both treePL and PATHd8 and both 4-locus and 5-locus trees, as well as previous studies (Wikström et al., 2001; Wang et al., 2009; Bell et al., 2010; Zanne et al., 2014; Magallón et al., 2015; Zeng et al., 2017). The ages of major rosid lineages estimated using the two dating methods and the two trees largely overlap with uncertainty intervals reported in previous studies (Fig 3). However, we did find that some clade ages (e.g., Celastrales, Crossosomatales, and Picramniales; Fig. 3) estimated in our study are younger and outside of the range of uncertainty reported in previous studies (Wikström et al., 2001; Wang et al., 2009; Bell et al., 2010; Zanne et al., 2014; Magallón et al., 2015), even though their placements agree with earlier studies (e.g., Wang et al., 2009; Magallón et al., 2015; APG IV, 2016). This discrepancy is likely due to poor taxon sampling of smaller rosid orders in previous studies; particularly, inclusion of a single species (e.g., Picramniales in the dating analyses of Zanne et al. 2014; Magallón et al. 2015) only allows stem age estimation. The greatly increased rosid sampling in the present study compared to earlier investigations (e.g., Wang et al., 2009; Bell et al., 2010; Magallón et al., 2015) could impact age estimation. Hence, we favor the results from treePL (both 4- and 5-locus; Table 2, Fig 2b). Although and PATHd8 were highly correlated $\left(\mathrm{R}^{2}=0.762\right)$. 
285

286

287

288

289

290

291

292

293

294

295

296

297

298

299

300

301

302

303

304

305

306

307

308

309

310

311

312

313

314

315

316

317

\section{Discussion}

Our 5-locus supermatrix represents the most comprehensive DNA data set yet compiled for the rosid clade. However, even with 19,740 ingroup species (out of 114,477 species estimated from OTT), our matrix is far from complete. Only 30,234 species of rosids (ca. 34\% estimated from Hinchliff et al., 2015) have any type of DNA data in GenBank (see also Folk et al., 2018), and after a series of filtering steps, our topology represents only $16.25 \%$ of all rosid species recorded in OTT (Table 1). This relative sampling level (less than 20\%) typifies most major clades of flowering plants (Eiserhardt et al., 2018; Folk et al., 2018).

Taxon sampling within rosids exhibits a strong phylogenetic bias (Fig. 1) in accumulation of molecular data $(p \approx 0)$. Among large families $(>1,000$ species $)$, the five with the poorest sampling (Polygalaceae, Myrtaceae, Rosaceae, Phyllanthaceae, and Malvaceae) have only $3.14 \%$ to $13.97 \%$ of species with at least one of the five loci sampled here in GenBank after matrix assembly and cleaning (cf. Table S2). For the five best-sampled families (Euphorbiaceae, Fabaceae, Passifloraceae, Brassicaceae, Cucurbitaceae), only $21.95 \%$ to $40.56 \%$ of species have one of the five loci. Hence, no large (> 1,000 species) family of rosids exceeds $45 \%$ species coverage, and most are below $30 \%$ coverage (Table S2), consistent with molecular sampling patterns across the angiosperms (Eiserhardt et al. 2018, Folk et al., 2018).

Our 5-locus topology is generally in close agreement with previous work (Wang et al., 2009; Soltis et al., 2011; Ruhfel et al., 2014; Sun et al., 2016), but with better overall resolution and without any cases of non-monophyletic families in the total-evidence trees (Fig. S1). Although the overall support across our tree is lower than that obtained in a previously published GenBank mining effort (Sun et al., 2016; Fig 2a), this is not surprising because: (1) studies have shown that BS values tend globally to decrease as the number of taxa increases (e.g., Sanderson \& Donoghue, 1996; Sanderson \& Wojciechowski, 2000; Soltis \& Soltis, 2003; here the 5-locus tree has $~ 2.2$ fold the species sampling of the 4-locus tree); and (2) the standard phylogenetic bootstrap method (e.g., as implemented by RAxML) tends to yield particularly low support for deep branches with large sampling scales (Lemoine et al., 2018).

While our ITS tree yielded low overall resolution for relationships within the rosids, adding ITS data improved the phylogenetic resolution within 14 families compared to that obtained in the 4-locus tree in Sun et al. (2016; Table S3). Additionally, some nodes remain 
318 unresolved across data partitions (e.g., placement of Zygophyllales, Myrtales, and Vitales;

319 Table S3), which likely reflect the rapid radiation of the rosid clade (Zhang et al., 2012, 2016;

320 Zhao et al., 2016; Zeng et al., 2017; Green Plant Consortium, submitted). The divergence

321 times here are generally consistent within methods and broadly congruent with the previous

322 literature (Fig. 3). Between the two estimation methods, divergence times from PATHd8

323 were younger than those from treePL (Figs. 2b and 3), but highly correlated.

324 Despite the importance of the rosids to terrestrial landscapes, our knowledge of this

325 clade remains limited (Folk et al., 2018), with species sampling gaps and bias that have

326 likewise persisted across flowering plants and in many other major clades of life (Smith \&

327 Brown, 2018). Transparently assessing and quantifying data gaps is crucial for studies using

328 large biodiversity data sets (Folk et al., 2018). Our exploration of phylogenetic sampling here

329 highlights the essential role of taxonomic resources like Open Tree for assessing sampling

330 gaps. We anticipate that similar analyses of cladewise sampling and explicit tests of

331 phylogenetic bias will become standard approaches in large-scale studies as these become

332 more numerous, and as discussion continues over their construction and use (e.g., Rabosky,

333 2015; Beaulieu \& O’Meara, 2018; Folk et al., 2018; Donoghue \& Edwards, 2019).

334 While limitations in sampling continue to hinder our understanding of angiosperm

335 evolution, growth of sequence databases continues to be rapid, and our updated supermatrix

336 effort has increased rosid species coverage by more than two-fold while recovering a

337 backbone that is largely robust. Given the importance of deeply sampled global phylogenies

338 for comparative biology (see Folk et al., 2018; Beaulieu \& O’Meara, 2018; Smith \& Brown,

339 2018; Allen et al., 2019), the data set we have assembled here will be an important resource

340 for macroevolutionary synthesis across a globally important clade.

\section{Acknowledgements}

342 This work was supported by the National Science Foundation (DEB-1208809 to D.E.S.),

343 Dimensions of Biodiversity US-China (DEB-1442280 to P.S.S. and D.E.S.), ABI Innovation

344 (DBI-1458640 to P.S.S. and D.E.S.), and National Natural Science Foundation of China

345 (Grant no. 31590822 to Z.D.C.). We thank Dr. Greg Stull for valuable suggestions on the

346 choice of fossil constraints, and Dr. Mark Miller and Dr. Pfeiffer Wayne from Cyber-

347 Infrastructure for Phylogenetic Research (CIPRES) Science Gateway for their extended

348 computation support. We thank the staff at the HiPerGator cluster at the University of Florida

349 and CIPRES for providing us extensive computational resources. 


\section{Author contributions}

351 The authors declare no conflict interests. D.E.S., P.S.S., Z.D.C., and M.S. designed the study;

352 M.S., S.A.S., and M.A.G. conducted GenBank data mining; M.S. and C.G.-A. performed

353 OpenTree mapping; M.S. did the phylogeny and dating analyses; M.S., C.G.-A., and D.E.S.

354 drafted the manuscript; R.A.F., D.E.S., S.A.S., M.A.G., P.S.S., Z.D.C., and R.P.G. revised

355 the manuscript. All authors contributed to and approved the final manuscript.

356

357 A pre-print version will be posted online shortly in bioRxiv (https://www.biorxiv.org/about-

358 biorxiv). 


\section{References}

Allen J, Folk RA, Soltis PS, Soltis DE, Guralnick RP. 2019. Big data and biodiversity: Big challenges and broad applications. Nature Plants 5: 11-13.

Anderson CL. 2007. Dating divergence times in phylogenies. Ph.D. Dissertation. Uppsala, Sweden: Uppsala University.

APG III. 2009. An update of the Angiosperm Phylogeny Group classification for the orders and families of flowering plants: APG III. Botanical Journal of the Linnean Society 161: 105-121.

APG IV. 2016. An update of the Angiosperm Phylogeny Group classification for the orders and families of flowering plants: APG IV. Botanical journal of the Linnean Society 181: 1-20.

Arabidopsis Genome Initiative. 2000. Analysis of the genome sequence of the flowering plant Arabidopsis thaliana. Nature 408: 796.

Barniske AM, Borsch T, Mueller K, Krug M, Worberg A, Neinhuis C, Quandt D. 2012. Phylogenetics of early branching eudicots: comparing phylogenetic signal across plastid introns, spacers, and genes. Journal of Systematics and Evolution 50: 85-108. Beaulieu JM, O’Meara BC. 2018. Can we build it? Yes we can, but should we use it? Assessing the quality and value of a very large phylogeny of campanulid angiosperms. American Journal of Botany 105: 417-432.

Bell C, Soltis D, Soltis P. 2010. The age and diversification of the angiosperms re-revisited. American Journal of Botany 97: 1296-1303.

Bininda-Emonds OR, Cardillo M, Jones KE, MacPhee RD, Beck RM, Grenyer R, Price SA, Vos RA, Gittleman JL, Purvis A. 2007. The delayed rise of present-day mammals. Nature 446: 507.

Boyce CK, Lee JE, Feild TS, Brodribb TJ, Zwieniecki MA. 2010. Angiosperms helped put the rain in the rainforests: The impact of plant physiological evolution on tropical biodiversity. Annals of the Missouri Botanical Garden 97: 527-540.

Britton T, Anderson CL, Jaquet D, Lundqvist S, Bremer K. 2006. PATHd8-a new method for estimating divergence times in large phylogenetic trees without a molecular clock [online]. Available from www.math.su.se/PATHd8 [accessed 1 May 2017].

Cantino PD, Doyle JA, Graham SW, Judd WS, Olmstead RG, Soltis DE, Soltis PS, Donoghue MJ. 2007. Towards a phylogenetic nomenclature of Tracheophyta. Taxon 56: $822-846$. 
392

393

394

395

396

397

398

399

400

401

402

403

404

405

406

407

408

409

410

411

412

413

414

415

416

417

418

419

420

421

422

423

424

425
Cayuela L, Granzow-de la CÍ, Albuquerque FS, Golicher DJ. 2012. Taxonstand: An R package for species names standardisation in vegetation databases. Methods in Ecology and Evolution 3: 1078-1083.

Davis CC, Wurdack KJ. 2004. Host-to-parasite gene transfer in flowering plants: phylogenetic evidence from Malpighiales. Science 305: 676-678.

Davis CC, Webb CO, Wurdack KJ, Jaramillo CA, Donoghue MJ. 2005. Explosive radiation of Malpighiales supports a Mid-Cretaceous origin of modern tropical rain forests. The American Naturalist 165: E36-E65.

Donoghue MJ, Edwards E J. 2019. Model clades are vital for comparative biology, and ascertainment bias is not a problem in practice: a response to Beaulieu and O'Meara. American Journal of Botany 106: 327-330.

Edger PP, Heidel-Fischer HM, Bekaert M, Rota J, Glöckner G, Platts AE, Heckel DG, Der JP, Wafula EK, Tang M et al. 2015. The butterfly plant arms-race escalated by gene and genome duplications. Proceedings of the National Academy of Sciences, USA 112: 8362-8366.

Edgar RC. 2004. MUSCLE: A multiple sequence alignment method with reduced time and space complexity. BMC Bioinformatics 5: 113.

Eiserhardt WL, Antonelli A, Bennett DJ, Botigué LR, Burleigh JG, Dodsworth S, Enquist BJ, et al. 2018. A roadmap for global synthesis of the plant tree of life. American Journal of Botany 105: 614-622.

Ericson PG, Anderson CL, Britton T, Elzanowski A, Johansson US, Källersjö M, Ohlson JI, Parsons TJ, Zuccon D, Mayr G. 2006. Diversification of Neoaves: integration of molecular sequence data and fossils. Biology Letters 2: 543-547.

Farr ER, Zijlstra G. 1996. Index Nominum Genericorum (Plantarum) [online]. Available from http: //botany.si.edu/ing/ [accessed 16 April 2017].

Farrell BD. 1998. "Inordinate fondness" explained: Why are there so many beetles? Science 281: 555 .

Feldberg K, Schneider H, Stadler T, Schäfer-Verwimp A, Schmidt AR, Heinrichs J. 2014. Epiphytic leafy liverworts diversified in angiosperm-dominated forests. Scientific Reports 4: 5974.

Folk RA, Sun M, Soltis PS, Smith SA, Soltis DE, Guralnick RP. 2018. Challenges of comprehensive taxon sampling in comparative biology: Wrestling with rosids. American Journal of Botany 105:433-445. doi: 10.1002/ajb2.1059

Green Plant Consortium (One Thousand Plant Transcriptomes Initiative). 2018. A 
phylogenomic view of evolutionary complexity in green plants. Nature, in review.

Govaert R. 2001. How many species of seed plants are there? Taxon 50: 1085-1090.

Hibbett DS, Matheny PB. 2009. The relative ages of ectomycorrhizal mushrooms and their plant hosts estimated using Bayesian relaxed molecular clock analyses. BMC Biology 7: 1 .

Hinchliff CE, Smith SA. 2014. Some limitations of public sequence data for phylogenetic inference (in plants). PLOS ONE 9: e98986.

Hinchliff CE, Smith SA, Allman JF, Burleigh JG, Chaudhary R, Coghill LM, Crandall KA, Deng J, Drew BT, Gazis R. 2015. Synthesis of phylogeny and taxonomy into a comprehensive tree of life. Proceedings National Academy of Sciences, USA 112: 12764-12769.

Huson DH, Scornavacca C. 2012. Dendroscope 3: an interactive tool for rooted phylogenetic trees and networks. Systematic Biology 61: 1061-1067.

Lemoine F, Domelevo Entfellner JB, Wilkinson E, Correia D, Dávila Felipe M, De Oliveira T, Gascuel O. 2018. Renewing Felsenstein's phylogenetic bootstrap in the era of big data. Nature 556: 452-456.

Letunic I, Bork P. 2016. Interactive tree of life (iTOL) v3: an online tool for the display and annotation of phylogenetic and other trees. Nucleic Acids Research 44: W242-W245.

Li HL, Wang W, Mortimer PE, Li RQ, Li DZ, Hyde KD, Xu JC, Soltis DE, Chen, Z. D. 2015. Large-scale phylogenetic analyses reveal multiple gains of actinorhizal nitrogen-fixing symbioses in angiosperms associated with climate change. Scientific Reports 5: 14023.

Jetz W, Thomas GH, Joy JB, Hartmann K, Mooers AO. 2012. The global diversity of birds in space and time. Nature 491: 444-448.

Junier T, Zdobnov EM. 2010. The Newick utilities: high-throughput phylogenetic tree processing in the UNIX shell. Bioinformatics 26: 1669-1670.

Katoh K, Kuma K, Toh H, Miyata T. 2005. MAFFT version 5: improvement in accuracy of multiple sequence alignment. Nucleic Acids Research 33: 511-518.

Kück P, Meusemann K. 2010. FASconCAT: convenient handling of data matrices. Molecular Phylogenetics and Evolution 56: 1115-1118.

Magallón S, Crane PR, Herendeen PS. 1999. Phylogenetic pattern, diversity, and diversification of eudicots. Annals of the Missouri Botanical Garden 86: 297-372.

Magallón S, Gómez-Acevedo S, Sánchez-Reyes LL, Hernández-Hernández T. 2015. A meta-calibrated timetree documents the early rise of flowering plant phylogenetic 
460

461

462

463

464

465

466

467

468

469

470

471

472

473

474

475

476

477

478

479

480

481

482

483

484

485

486

487

488

489

490

491

492

493

diversity. New Phytologist 207: 437-453.

Moreau CS, Bell CD, Vila R, Archibald SB, Pierce NE. 2006. Phylogeny of the ants: diversification in the age of angiosperms. Science 312: 101-104.

Moreau CS, Bell CD. 2013. Testing the museum versus cradle tropical biological diversity hypothesis: phylogeny, diversification, and ancestral biogeographic range evolution of the ants. Evolution 67: 2240-2257.

Moore MJ, Soltis PS, Bell CD, Burleigh JG, Soltis DE. 2010. Phylogenetic analysis of 83 plastid genes further resolved the early diversification of eudicots. Proceedings of the National Academy of Sciences, USA 107: 4623-4628.

Pattengale ND, Alipour M, Bininda-Emonds OR, Moret BM, Stamatakis A. 2010a. How many bootstrap replicates are necessary? Journal of Computational Biology 17: 337 354.

Pattengale ND, Swenson KM, Moret BME. 2010b. Uncovering hidden phylogenetic consensus. In: Borodovsky M, Gogarten JPeter, Przytycka TM, Rajasekaran S eds. Bioinformatics research and applications. Berlin, Germany: Springer-Verlag. 128139.

Pennell MW, Eastman JM, Slater GJ, Brown JW, Uyeda JC, FitzJohn RG, Alfaro ME, Harmon LJ. 2014. geiger v2.0: an expanded suite of methods for fitting macroevolutionary models to phylogenetic trees. Bioinformatics 15: 2216-2218.

Rabosky DL. 2015. No substitute for real data: A cautionary note on the use of phylogenies from birth-death polytomy resolvers for downstream comparative analyses. Evolution 69: 3207-3216.

Ricklefs RE. 2007. Estimating diversification rates from phylogenetic information. Trends in Ecology \& Evolution 22: 601-610.

Rodman JE, Soltis PS, Soltis DE, Sytsma K, Karol K. 1998. Parallel evolution of glucosinolate biosynthesis inferred from congruent nuclear and plastid gene phylogenies. American Journal of Botany 85: 997-997.

Roelants K, Gower DJ, Wilkinson M, Loader SP, Biju SD, Guillaume K, Moriau L, Bossuyt F. 2007. Global patterns of diversification in the history of modern amphibians. Proceedings of the National Academy of Sciences, USA 104: 887-892.

Ruhfel BR, Gitzendanner MA, Soltis DE, Soltis PS, Burleigh JG. 2014. From algae to angiosperms - inferring the phylogeny of green plants (Viridiplantae) from 360 plastid genomes. BMC Evolutionary Biology 14: 23.

Sanderson MJ, Donoghue MJ. 1996. The relationship between homoplasy and confidence in 
494

495

496

497

498

499

500

501

502

503

504

505

506

507

508

509

510

511

512

513

514

515

516

517

518

519

520

521

522

523

524

525

526

527

a phylogenetic tree. In: Sanderson MJ, Hufford L, eds. Homoplasy: The recurrence of similarity in evolution. San Diego, USA: Academic Press. 67-89.

Sanderson MJ, Wojciechowski MF. 2000. Improved bootstrap confidence limits in largescale phylogenies with an example from Neo-Astragalus (Leguminosae). Systematic Biology 49: 671-685.

Sato S, Nakamura Y, Kaneko T, Asamizu E, Kato T, Nakao M, Sasamoto S, Watanabe A, Ono A, Kawashima K et al. 2008. Genome structure of the legume, Lotus japonicus. DNA research 15: 227-239.

Sauquet H, Ho S, Gandolfo M, Jordan G, Wilf P, Cantrill D, Bayly M, Bromham L, Brown G, Carpenter R. 2012. Testing the impact of calibration on molecular divergence times using a fossil-rich group: the case of Nothofagus (Fagales). Systematic Biology 61: 298-313.

Schmutz J, Cannon SB, Schlueter J, Ma J, Mitros T, Nelson W, Hyten DL, Song Q, Thelen JJ, Cheng J et al. 2010. Genome sequence of the palaeopolyploid soybean. Nature 463: $178-183$.

Schmutz J, McClean PE, Mamidi S, Wu GA, Cannon SB, Grimwood J, Jenkins J, Shu S, Song Q, Chavarro C et al. 2014. A reference genome for common bean and genomewide analysis of dual domestications. Nature Genetics 46: 707-713.

Schneider H, Schuettpelz E, Pryer KM, Cranfill R. 2004. Ferns diversified in the shadow of angiosperms. Nature 428: 553.

Smith SA, Beaulieu JM, Donoghue MJ 2009. Mega-phylogeny approach for comparative biology: An alternative to supertree and supermatrix approaches. BMC Evolution Biology 9: 37.

Smith SA, Beaulieu JM, Donoghue M. 2010. An uncorrelated relaxed-clock analysis suggests an earlier origin for flowering plants. Proceedings of the National Academy of Sciences, USA 107: 5897-5902.

Smith SA, Beaulieu JM, Stamatakis A, Donoghue MJ. 2011. Understanding Angiosperm diversification using small and large phylogenetic trees. American Journal of Botany 98: 404-414.

Smith SA, O’Meara BC. 2012. treePL: divergence time estimation using penalized likelihood for large phylogenies. Bioinformatics 28: 689-2690.

Smith SA, Brown JW. 2018. Constructing a broadly inclusive seed plant phylogeny. American Journal of Botany 105: 1-13. doi: 10.1002/ajb2.1019

Soltis DE, Soltis PS, Morgan DR, Swensen SM, Mullin BC, Dowd JM, Martin P G. 1995. 
Chloroplast gene sequence data suggest a single origin of the predisposition for symbiotic nitrogen fixation in angiosperms. Proceedings of the National Academy of Sciences, USA 92: 2647-2651.

Soltis DE, Soltis PS, Endress PK, Chase MW. 2005. Phylogeny and evolution of angiosperms. Sunderland, MA, USA: Sinauer Associates.

Soltis DE, Gitzendanner MA, Soltis PS. 2007. A 567-taxon data set for angiosperms: The challenges posed by Bayesian analyses of large data sets. International Journal of Plant Sciences 168: 137-157.

Soltis DE, Moore MJ, Burleigh JG, Bell CD, Soltis PS. 2010. Assembling the angiosperm tree of life: progress and future prospects. Annals of the Missouri Botanical Garden 97: 514-526.

Soltis DE, Smith SA, Cellinese N, Wurdack KJ, Tank DC, Brockington SF, RefulioRodriguez NF, Walker JB, Moore MJ, Carlsward BS et al. 2011. Angiosperm phylogeny: 17 genes, 640 taxa. American Journal of Botany 98: 704-730.

Soltis DE, Soltis PS. 2016. Mobilizing and integrating big data in studies of spatial and phylogenetic patterns of biodiversity. Plant Diversity 38: 264-270.

Soltis PS, Soltis DE. 2003. Applying the bootstrap in phylogeny reconstruction. Statistical Science 8: 256-267.

Soltis PS, Soltis DE. 2004. The origin and diversification of angiosperms. American Journal of Botany 91: 1614-1626.

Soltis PS, Soltis DE, Chase MW, Endress PK, Crane PR. 2004. The diversification of flowering plants. In: Cracraft J, Donoghue M, eds. The tree of life. Oxford, UK \& New York, USA: Oxford University Press. 154-167.

Stamatakis A. 2014. RAxML version 8: a tool for phylogenetic analysis and post-analysis of large phylogenies. Bioinformatics 30: 1312-1313.

Stevens PF. 2001 onwards. Angiosperm phylogeny website, Version 14, July 2017 [online]. Available from http://www.mobot.org/MOBOT/research/APweb/ [accessed 1 January 2018].

Sun M, Soltis DE, Soltis PS, Zhu X, Burleigh JG, Chen ZD. 2015. Deep phylogenetic incongruence in the angiosperm clade Rosidae. Molecular Phylogenetics and Evolution 83: 156-166.

Sun M, Naeem R, Su JX, Cao ZY, J. Burleigh G, Soltis PS, Soltis DE, Chen ZD. 2016. Phylogeny of the Rosidae: A dense taxon sampling analysis. Journal of Systematic and Evolution 54: 363-391. 
562 Tamura K, Stecher G, Peterson D, Filipski A, Kumar S. 2013. MEGA6: Molecular Evolutionary Genetics Analysis Version 6.0. Molecular Biology and Evolution 30: $2725-2729$.

Testo W, Sundue M. 2016. A 4000-species dataset provides new insight into the evolution of ferns. Molecular Phylogenetics and Evolution 105: 200-211.

Thomas GH, Hartmann K, Jetz W, Joy JB, Mimoto A, Mooers AO. 2013. PASTIS: an R package to facilitate phylogenetic assembly with soft taxonomic inferences. Methods in Ecology and Evolution 4: 1011-1017. doi:10.1111/2041-210X.12117

Varshney RK, Chen WB, Li YP, Bharti AK, Saxena RK, Schlueter JA, Donoghue MTA, Azam S, Fan GY, Whaley AM et al. 2012. Draft genome sequence of pigeonpea (Cajanus cajan), an orphan legume crop of resource-poor farmers. Nature Biotechnology 30: 83-89.

Varshney RK, Song C, Saxena RK, Azam S, Yu S, Sharpe AG, Cannon S, Baek J, Rosen BD, Tar'an B et al. 2013. Draft genome sequence of chickpea (Cicer arietinum) provides a resource for trait improvement. Nature biotechnology 31: 240-246.

Wang H, Moore MJ, Soltis PS, Bell CD, Brockington SF, Alexandre R, Davis CC, Latvis M, Manchester SR, Soltis DE. 2009. Rosid radiation and the rapid rise of angiospermdominated forests. Proceedings of the National Academy of Sciences, USA 106: 3853-3858.

Wang X, Wang H, Wang J, Sun R, Wu J, Liu S, Bai Y, Mun J, Bancroft I, Cheng F et al. 2011. The genome of the mesopolyploid crop species Brassica rapa. Nature Genetics 43: 1035-1039.

Watkins JJE, Cardelús CL. 2012. Ferns in an angiosperm world: Cretaceous radiation into the epiphytic niche and diversification on the forest floor. International Journal of Plant Sciences 173: 695-710.

Wikström N, Savolainen V, Chase MW. 2001. Evolution of the angiosperms: Calibrating the family tree. Proceedings of the Royal Society of London, B, Biological Sciences 268: 2211-2220. recent. Science 289: 291-294.

Worberg A, Quandt D, Barnkske AM, Lohne C, Hilu KW, Borsch T. 2007. Phylogeny of basal eudicots: Insights from non-coding and rapidly evolving DNA. Organisms Diversity and Evolution 7: 55-77. 
596

597

598

599

600

601

602

603

604

605

606

607

608

609

610

611

612

613

614

615

616

617

618

619

620

621

Xi Z, Ruhfel BR, Schaefer H, Amorim AM, Sugumaran M, Wurdack KJ, Endress PK, Matthews M, Stevens PF, Mathews S et al. 2012. Phylogenomics and a posteriori data partitioning resolve the Cretaceous angiosperm radiation in Malpighiales. Proceedings National Academy of Sciences, USA 109: 17519-1752.

Young ND, Debellé F, Oldroyd GE, Geurts R, Cannon SB, Udvardi MK, Benedito VA, Mayer KFX, Gouzy J, Schoof H et al. 2011. The Medicago genome provides insight into the evolution of rhizobial symbioses. Nature 480: 520-524.

Zanne AE, Tank DC, Cornwell WK, Eastman JM, Smith SA, FitzJohn RG, McGlinn DJ, O'Meara BC, Moles AT, Reich PB et al. 2014. Three keys to the radiation of angiosperms into freezing environments. Nature 506: 89-92.

Zeng L, Zhang N, Zhang Q, Endress PK, Huang J, Ma H. 2017. Resolution of deep eudicot phylogeny and their temporal diversification using nuclear genes from transcriptomic and genomic datasets. New Phytologist 214: 1338-1354.

Zhang N, Zeng LP, Shan HY, Ma H. 2012. Highly conserved low-copy nuclear genes as effective markers for phylogenetic analyses in angiosperms. New Phytologists 195: 923-937.

Zhang N, Wen J, Zimmer EA. 2016. Another look at the phylogenetic position of the grape order Vitales: Chloroplast phylogenomics with an expanded sampling of key lineages, Molecular Phylogenetics and Evolution 101: 216-223.

Zhao L, Li X, Zhang N, Zhang SD, Yi TS, Ma H, Guo ZH, Li DZ. 2016. Phylogenomic analyses of large-scale nuclear genes provide new insights into the evolutionary relationships within the rosids. Molecular Phylogenetics and Evolution 105: 166-176.

Zhu XY, Chase MW, Qiu YL, Kong HZ, Dilcher DL, Li JH, Chen ZD. 2007. MatR sequences help to resolve deep phylogenetic relationships in rosids. BMC Evolutionary Biology 7: 217. 
Table 1. Ordinal-level summary sampling table for the 5-locus rosid supermatrix ("Matrix") compared to the rosid clade of the Open Tree Taxonomy (“OTT”) database v. 3.0 (https://devtree.opentreeoflife.org/about/taxonomy-version/ott3.0; Hinchliff et al., 2015) and matching taxon names between these data sets. Orders follow APG IV (2016). A summary table at the family level is available in Table S2.

\begin{tabular}{|c|c|c|c|c|}
\hline Order & $\begin{array}{l}\text { Match (Matrix genera)/OTT } \\
\text { genera }\end{array}$ & Matched genus \% & $\begin{array}{l}\text { Match (Matrix species)/OTT } \\
\text { species }\end{array}$ & Matched species \% \\
\hline Brassicales & $357(369) / 502$ & $71.12 \%$ & $1693(1843) / 5940$ & $28.50 \%$ \\
\hline Celastrales & $68(69) / 111$ & $61.26 \%$ & $272(281) / 1499$ & $18.15 \%$ \\
\hline Crossosomatales & $13(13) / 14$ & $92.86 \%$ & $24(24) / 82$ & $29.27 \%$ \\
\hline Cucurbitales & $117(125) / 133$ & $87.97 \%$ & $823(863) / 3094$ & $26.60 \%$ \\
\hline Fabales & $657(668) / 864$ & $76.04 \%$ & $5311(5678) / 24191$ & $21.95 \%$ \\
\hline Fagales & $36(38) / 74$ & $48.65 \%$ & $496(540) / 2263$ & $21.92 \%$ \\
\hline Geraniales & $15(18) / 20$ & $75.00 \%$ & $295(305) / 962$ & $30.67 \%$ \\
\hline Huerteales & $6(6) / 6$ & $100.00 \%$ & $7(7) / 30$ & $23.33 \%$ \\
\hline Malpighiales & $586(596) / 891$ & $65.77 \%$ & $3703(3868) / 21316$ & $17.37 \%$ \\
\hline Malvales & $255(257) / 405$ & $62.96 \%$ & $1285(1349) / 7771$ & $16.54 \%$ \\
\hline Myrtales & $257(263) / 475$ & $54.11 \%$ & $1286(1373) / 15529$ & $8.28 \%$ \\
\hline Oxalidales & $43(45) / 69$ & $62.32 \%$ & $182(193) / 2207$ & $8.25 \%$ \\
\hline Picramniales & $2(2) / 3$ & $66.67 \%$ & $5(5) / 57$ & $8.77 \%$ \\
\hline Rosales & $217(227) / 359$ & $60.45 \%$ & $1694(1787) / 20620$ & $8.22 \%$ \\
\hline Sapindales & $342(347) / 551$ & $62.07 \%$ & $1361(1434) / 7421$ & $18.34 \%$ \\
\hline Vitales & $9(9) / 15$ & $60.00 \%$ & $110(119) / 1155$ & $9.52 \%$ \\
\hline Zygophyllales & $18(18) / 27$ & $66.67 \%$ & $60(71) / 340$ & $17.65 \%$ \\
\hline Total & $2998(3070) / 4519$ & $66.34 \%$ & $18607(19740) / 114477$ & $16.25 \%$ \\
\hline
\end{tabular}


Table 2. Summary table of ages estimated for rosid major clades by treePL and PATHd8 based on the tree inferred here ("5-locus") and that inferred in Sun et al. 2016 ("4-locus"). The age unit is million years ago (Myr).

\begin{tabular}{|c|c|c|c|c|}
\hline \multirow{2}{*}{ Clade } & \multicolumn{2}{|c|}{ 5-locus } & \multicolumn{2}{|c|}{ 4-locus } \\
\hline & Age treePL & Age PATHd8 & Age treePL & Age PATHd8 \\
\hline Fabids & 117.03 & 89.80 & 121.11 & 94.95 \\
\hline Fagales & 95.60 & 83.50 & 100.83 & 83.50 \\
\hline Betulaceae & 60.64 & 59.80 & 59.80 & 59.80 \\
\hline Casuarinaceae & 27.57 & 46.63 & 27.06 & 41.62 \\
\hline Fagaceae & 66.27 & 61.12 & 67.04 & 69.46 \\
\hline Juglandaceae & 72.55 & 69.39 & 69.66 & 66.60 \\
\hline Myricaceae & 30.08 & 27.63 & 26.18 & 27.97 \\
\hline Nothofagaceae & 18.53 & 11.42 & 18.26 & 11.30 \\
\hline Ticodendraceae & 66.67 & 59.80 & 64.52 & 63.23 \\
\hline Cucurbitales & 111.95 & 65.06 & 113.39 & 53.48 \\
\hline Anisophylleaceae & 48.13 & 35.30 & 49.44 & 39.52 \\
\hline Apodanthaceae & 70.73 & 65.06 & 74.69 & 48.60 \\
\hline Begoniaceae & 52.11 & 35.40 & 23.74 & 20.39 \\
\hline Cucurbitaceae & 34.91 & 28.17 & 42.07 & 29.20 \\
\hline Tetramelaceae & 19.21 & 9.01 & 22.57 & 12.15 \\
\hline Corynocarpaceae & 6.95 & 3.62 & 6.96 & 2.86 \\
\hline Coriariaceae & 14.04 & 7.82 & 22.97 & 10.15 \\
\hline Datiscaceae & 8.47 & 4.54 & 9.54 & 5.24 \\
\hline Rosales & 107.52 & 89.80 & 111.03 & 89.80 \\
\hline Cannabaceae & 67.73 & 65.50 & 67.26 & 65.50 \\
\hline Elaeagnaceae & 27.41 & 20.06 & 28.70 & 27.79 \\
\hline Moraceae & 46.03 & 28.78 & 40.49 & 16.31 \\
\hline
\end{tabular}




\begin{tabular}{|c|c|c|c|c|}
\hline Rhamnaceae & 74.55 & 48.60 & 80.11 & 61.70 \\
\hline Rosaceae & 89.80 & 89.80 & 89.80 & 89.80 \\
\hline Ulmaceae & 59.41 & 32.53 & 88.93 & 21.49 \\
\hline Urticaceae & 60.28 & 51.05 & 68.70 & 33.25 \\
\hline Dirachmaceae & 88.51 & 70.60 & 96.98 & 70.60 \\
\hline Barbeyaceae & 84.47 & 53.33 & 90.03 & 70.60 \\
\hline Fabales & 96.58 & 59.90 & 105.41 & 75.15 \\
\hline Fabaceae & 83.90 & 55.80 & 93.77 & 65.37 \\
\hline Polygalaceae & 60.89 & 55.80 & 72.51 & 13.46 \\
\hline Surianaceae & 47.39 & 15.50 & 53.52 & 21.96 \\
\hline Quillajaceae & 90.75 & 26.59 & 98.52 & 36.49 \\
\hline Malpighiales & 114.67 & 89.30 & 114.47 & 89.30 \\
\hline Achariaceae & 54.72 & 14.37 & 64.21 & 25.88 \\
\hline Bonnetiaceae & 70.08 & 58.52 & 71.27 & 58.67 \\
\hline Calophyllaceae & 55.73 & 21.85 & 47.53 & 17.35 \\
\hline Caryocaraceae & 20.12 & 5.20 & 22.18 & 8.73 \\
\hline Centroplacaceae & 74.12 & 15.13 & 77.14 & 23.34 \\
\hline Chrysobalanaceae & 22.13 & 10.69 & 27.61 & 16.17 \\
\hline Clusiaceae & 52.63 & 27.13 & 52.05 & 22.91 \\
\hline Dichapetalaceae & 17.65 & 5.96 & 22.97 & 10.87 \\
\hline Elatinaceae & 50.37 & 17.24 & 51.62 & 21.99 \\
\hline Erythroxylaceae & 46.31 & 17.55 & 55.76 & 26.26 \\
\hline Euphorbiaceae & 63.30 & 38.14 & 99.38 & 41.95 \\
\hline Humiriaceae & 33.90 & 33.90 & 33.90 & 33.90 \\
\hline Hypericaceae & 81.66 & 63.84 & 81.46 & 63.49 \\
\hline Irvingiaceae & 5.19 & 1.57 & 6.10 & 2.61 \\
\hline Ixonanthaceae & 23.76 & 8.15 & 31.28 & 13.56 \\
\hline \multirow[t]{2}{*}{ Lacistemataceae } & 7.82 & 2.19 & 9.54 & 3.73 \\
\hline & & 24 & & \\
\hline
\end{tabular}




\begin{tabular}{|c|c|c|c|c|}
\hline Linaceae & 58.84 & 25.10 & 60.48 & 37.36 \\
\hline Malpighiaceae & 53.17 & 33.00 & 47.75 & 33.00 \\
\hline Ochnaceae & 51.42 & 15.36 & 54.39 & 25.49 \\
\hline Pandaceae & 38.67 & 8.97 & 42.54 & 15.19 \\
\hline Passifloraceae & 63.15 & 33.74 & 83.25 & 3.24 \\
\hline Peraceae & 53.84 & 13.68 & 68.14 & 22.94 \\
\hline Phyllanthaceae & 68.83 & 28.13 & 101.43 & 50.67 \\
\hline Picrodendraceae & 35.15 & 12.86 & 44.13 & 21.99 \\
\hline Podostemaceae & 80.18 & 89.30 & 82.99 & 89.30 \\
\hline Putranjivaceae & 18.11 & 6.86 & 16.72 & 6.28 \\
\hline Rafflesiaceae & 81.48 & 41.45 & 70.24 & 41.13 \\
\hline Rhizophoraceae & 59.88 & 33.90 & 59.74 & 33.90 \\
\hline Salicaceae & 64.37 & 48.00 & 71.33 & 48.00 \\
\hline Trigoniaceae & 38.07 & 15.32 & 50.40 & 26.28 \\
\hline Violaceae & 57.17 & 27.34 & 68.43 & 47.89 \\
\hline Balanopaceae & 17.87 & 3.61 & 24.51 & 6.52 \\
\hline Ctenolophonaceae & 80.30 & 34.51 & 109.65 & 52.48 \\
\hline Euphroniaceae & 46.86 & 23.35 & 64.26 & 37.35 \\
\hline Goupiaceae & 75.00 & 32.02 & 87.00 & 54.34 \\
\hline Lophopyxidaceae & 60.81 & 19.39 & 77.63 & 31.51 \\
\hline Celastrales & 89.44 & 45.93 & 94.99 & 54.88 \\
\hline Lepidobotryaceae & 12.11 & 3.25 & 12.84 & 4.99 \\
\hline Celastraceae & 67.89 & 37.82 & 76.39 & 38.90 \\
\hline Oxalidales & 112.85 & 79.20 & 114.28 & 79.20 \\
\hline Connaraceae & 35.38 & 6.59 & 24.76 & 10.10 \\
\hline Cunoniaceae & 43.50 & 79.20 & 32.67 & 65.56 \\
\hline Elaeocarpaceae & 61.70 & 61.70 & 61.70 & 61.70 \\
\hline \multirow[t]{2}{*}{ Huaceae } & 14.23 & 4.30 & 16.56 & 6.62 \\
\hline & & 25 & & \\
\hline
\end{tabular}




\begin{tabular}{|c|c|c|c|c|}
\hline Oxalidaceae & 52.72 & 21.00 & 46.59 & 30.05 \\
\hline Cephalotaceae & 77.57 & 53.13 & 70.61 & 79.20 \\
\hline Brunelliaceae & 2.65 & 3.41 & 3.71 & 3.27 \\
\hline Zygophyllales & 96.67 & 42.02 & 96.95 & 74.54 \\
\hline Zygophyllaceae & 91.38 & 41.07 & 90.94 & 69.52 \\
\hline Krameriaceae & 31.36 & 8.25 & 18.16 & 7.87 \\
\hline Malvids & 116.49 & 89.30 & 120.33 & 91.47 \\
\hline Brassicales & 86.82 & 86.66 & 95.92 & 89.30 \\
\hline Akaniaceae & 4.10 & 1.86 & 3.07 & 1.19 \\
\hline Brassicaceae & 36.20 & 30.70 & 45.27 & 32.55 \\
\hline Capparaceae & 38.94 & 17.68 & 43.31 & 22.21 \\
\hline Caricaceae & 26.58 & 13.58 & 28.74 & 16.33 \\
\hline Cleomaceae & 38.58 & 24.01 & 47.85 & 29.53 \\
\hline Gyrostemonaceae & 6.80 & 3.34 & 9.87 & 5.39 \\
\hline Limnanthaceae & 13.78 & 8.26 & 11.54 & 7.52 \\
\hline Resedaceae & 53.78 & 44.91 & 58.24 & 43.56 \\
\hline Salvadoraceae & 26.97 & 14.59 & 40.37 & 24.73 \\
\hline Tropaeolaceae & 40.20 & 20.73 & 13.06 & 7.64 \\
\hline Bataceae & 32.77 & 20.86 & 36.62 & 24.73 \\
\hline Emblingiaceae & 52.88 & 24.59 & 61.28 & 25.27 \\
\hline Koeberliniaceae & 67.42 & 50.48 & 77.00 & 55.39 \\
\hline Moringaceae & 12.17 & 5.91 & 14.61 & 6.99 \\
\hline Pentadiplandraceae & 63.01 & 62.42 & 70.52 & 70.43 \\
\hline Setchellanthaceae & 78.46 & 79.01 & 87.32 & 89.30 \\
\hline Tovariaceae & 52.88 & 24.59 & 61.28 & 25.27 \\
\hline Malvales & 100.59 & 69.12 & 101.97 & 68.91 \\
\hline Bixaceae & 50.29 & 24.36 & 54.37 & 26.98 \\
\hline Cistaceae & 45.68 & $\begin{array}{c}34.47 \\
26\end{array}$ & 50.40 & 45.35 \\
\hline
\end{tabular}




\begin{tabular}{|c|c|c|c|c|}
\hline Cytinaceae & 73.43 & 67.35 & 73.58 & 55.17 \\
\hline Dipterocarpaceae & 35.80 & 17.07 & 36.05 & 19.22 \\
\hline Malvaceae & 50.85 & 36.94 & 44.04 & 25.61 \\
\hline Muntingiaceae & 42.72 & 21.12 & 49.82 & 25.44 \\
\hline Neuradaceae & 10.59 & 5.59 & 11.18 & 5.71 \\
\hline Sarcolaenaceae & 12.94 & 6.04 & 13.37 & 6.31 \\
\hline Sphaerosepalaceae & 11.85 & 4.89 & 13.20 & 5.20 \\
\hline Thymelaeaceae & 48.55 & 40.20 & 47.79 & 12.59 \\
\hline Picramniales/Picramniaceae & 36.78 & 9.65 & 36.91 & 14.80 \\
\hline Huerteales & 61.57 & 37.20 & 67.93 & 37.20 \\
\hline Dipentodontaceae & 38.06 & 10.16 & 37.79 & 15.23 \\
\hline Tapisciaceae & 37.20 & 37.20 & 37.20 & 37.20 \\
\hline Petenaeaceae & 56.88 & 14.16 & 61.53 & 22.34 \\
\hline Gerrardinaceae & 56.88 & 14.16 & 61.53 & 22.34 \\
\hline Sapindales & 88.96 & 65.50 & 82.21 & 65.50 \\
\hline Anacardiaceae & 45.59 & 32.35 & 50.69 & 47.00 \\
\hline Burseraceae & 43.87 & 31.43 & 31.32 & 32.09 \\
\hline Meliaceae & 48.60 & 48.60 & 49.04 & 48.60 \\
\hline Nitrariaceae & 62.91 & 17.63 & 32.49 & 16.91 \\
\hline Rutaceae & 65.50 & 65.50 & 65.50 & 65.50 \\
\hline Sapindaceae & 64.76 & 55.80 & 60.52 & 55.80 \\
\hline Simaroubaceae & 46.19 & 12.04 & 47.98 & 21.83 \\
\hline Kirkiaceae & 3.46 & 0.92 & 3.97 & 1.49 \\
\hline Biebersteiniaceae & 19.11 & 5.12 & 17.58 & 7.59 \\
\hline Crossosomatales & 88.66 & 28.40 & 90.75 & 34.68 \\
\hline Crossosomataceae & 17.62 & 4.88 & 16.78 & 8.65 \\
\hline Staphyleaceae & 28.40 & 28.40 & 28.40 & 28.40 \\
\hline Strasburgeriaceae & 20.74 & $\begin{array}{l}4.68 \\
27\end{array}$ & 23.87 & 8.25 \\
\hline
\end{tabular}




\begin{tabular}{|c|c|c|c|c|}
\hline Aphloiaceae & 75.92 & 15.79 & 78.94 & 27.26 \\
\hline Geissolomataceae & 46.62 & 9.63 & 56.37 & 17.05 \\
\hline Guamatelaceae & 40.90 & 6.30 & 31.80 & 10.86 \\
\hline Stachyuraceae & 2.84 & 0.63 & 3.67 & 1.01 \\
\hline Geraniales + Myrtales & 116.49 & 88.20 & 121.39 & 96.30 \\
\hline Geraniales & 107.69 & 47.69 & 117.77 & 81.03 \\
\hline Geraniaceae & 74.66 & 32.08 & 97.14 & 77.94 \\
\hline Francoaceae & 97.34 & 29.59 & 104.62 & 36.60 \\
\hline Myrtales & 95.00 & 88.20 & 95.00 & 88.20 \\
\hline Combretaceae & 51.58 & 16.24 & 42.78 & 12.45 \\
\hline Crypteroniaceae & 18.04 & 9.91 & 17.77 & 9.68 \\
\hline Lythraceae & 72.66 & 70.60 & 71.98 & 70.60 \\
\hline Melastomataceae & 49.25 & 51.74 & 47.35 & 60.23 \\
\hline Myrtaceae & 64.10 & 55.80 & 64.27 & 55.80 \\
\hline Onagraceae & 49.56 & 40.09 & 60.65 & 53.07 \\
\hline Penaeaceae & 34.38 & 17.22 & 26.29 & 21.19 \\
\hline Vochysiaceae & 39.18 & 26.95 & 36.65 & 27.24 \\
\hline Alzateaceae & 52.22 & 26.13 & 32.38 & 26.29 \\
\hline Vitales/Vitaceae & 75.77 & 66.00 & 78.27 & 66.37 \\
\hline Rosids & 117.93 & 89.80 & 122.62 & 104.20 \\
\hline
\end{tabular}




\section{Figure Legends:}

Fig. 1. The 5-locus rosid phylogeny showing sampling coverage of sequence data for the 5 loci. This comparison shows substantial phylogenetic bias in each of the 5 loci sampled in the rosid matrix based on presence/absence heatmap layers. The five layers are labeled as $m a t R, a t p B, r b c L, m a t K$, and ITS from inside toward the outer edge. Species with black tips at each layer mean sequence data are available for a specific locus. Each order is labeled and colored, so phylogenetic bias of DNA data can be viewed by the rough distribution of the black and gray tips within and/or among each order (cf. Tables 1, S2 for further percentage details).

Fig. 2. Comparison of phylogenetic resolution (a) and divergence time estimation (b) between the 4-locus, 8,855-taxon rosid phylogeny and the 5-locus, 19,740-taxon rosid phylogeny. BS stands for bootstrap. Orange denotes the treePL method, and blue denotes the PATHd8 method in panel (b).

Fig. 3. Comparison of crown ages for major rosid clades reported in this study, Wikström et al. (2001), Wang et al. (2009), Bell et al. (2010), Zanne et al. (2014), and Magallón et al. (2015). Error bars represent age ranges reported for the given node. Red hollow circles and diamonds stand for ages estimated from the 4-locus tree; solid symbols are estimated from the 5-locus tree; the color bars at the bottom of the plot correspond to the orders in Fig. 1. In several previous studies, only a single species was sampled for small clades such as Picramniales, preventing the estimation of crown ages; in these cases only the stem age is given here. 


\section{Supporting Information}

Fig. S1 The best ML tree obtained from the RAxML analysis.

Table S1. Information on the 59 rosid calibration constraints used in this study.

Table S2. Family-level summary sampling table for the 5-locus supermatrix ("Matrix")

compared to the rosid clade of the Open Tree Taxonomy ("OTT") database v.3.0

(https://devtree.opentreeoflife.org/about/taxonomy-version/ott3.0; Hinchliff et al., 2015) and matched taxon names between these data sets.

Table S3. List of non-monophyletic families in the matR and ITS locus trees. 
(a)

BS Support

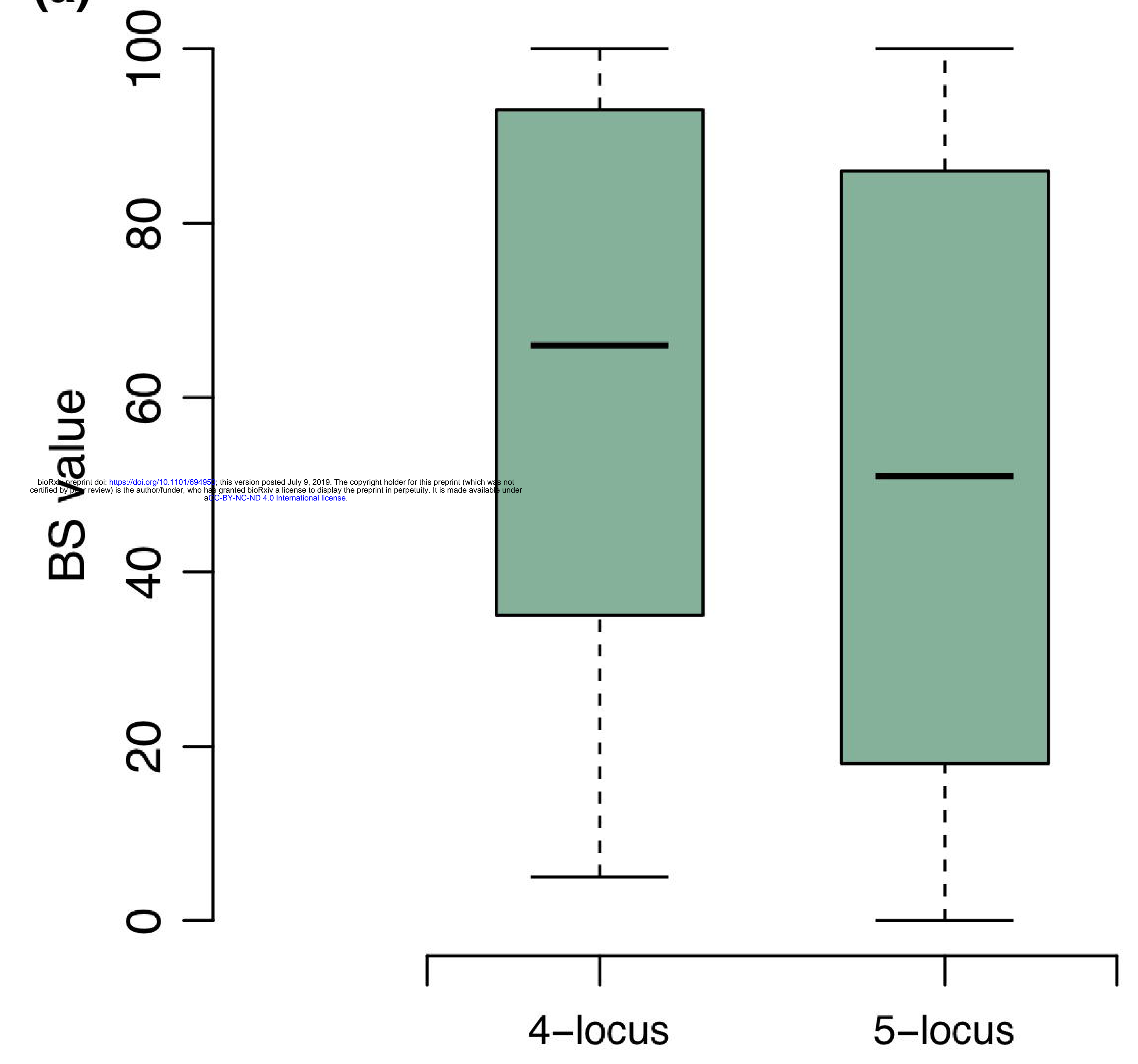

(b)

\section{Time Calibration}

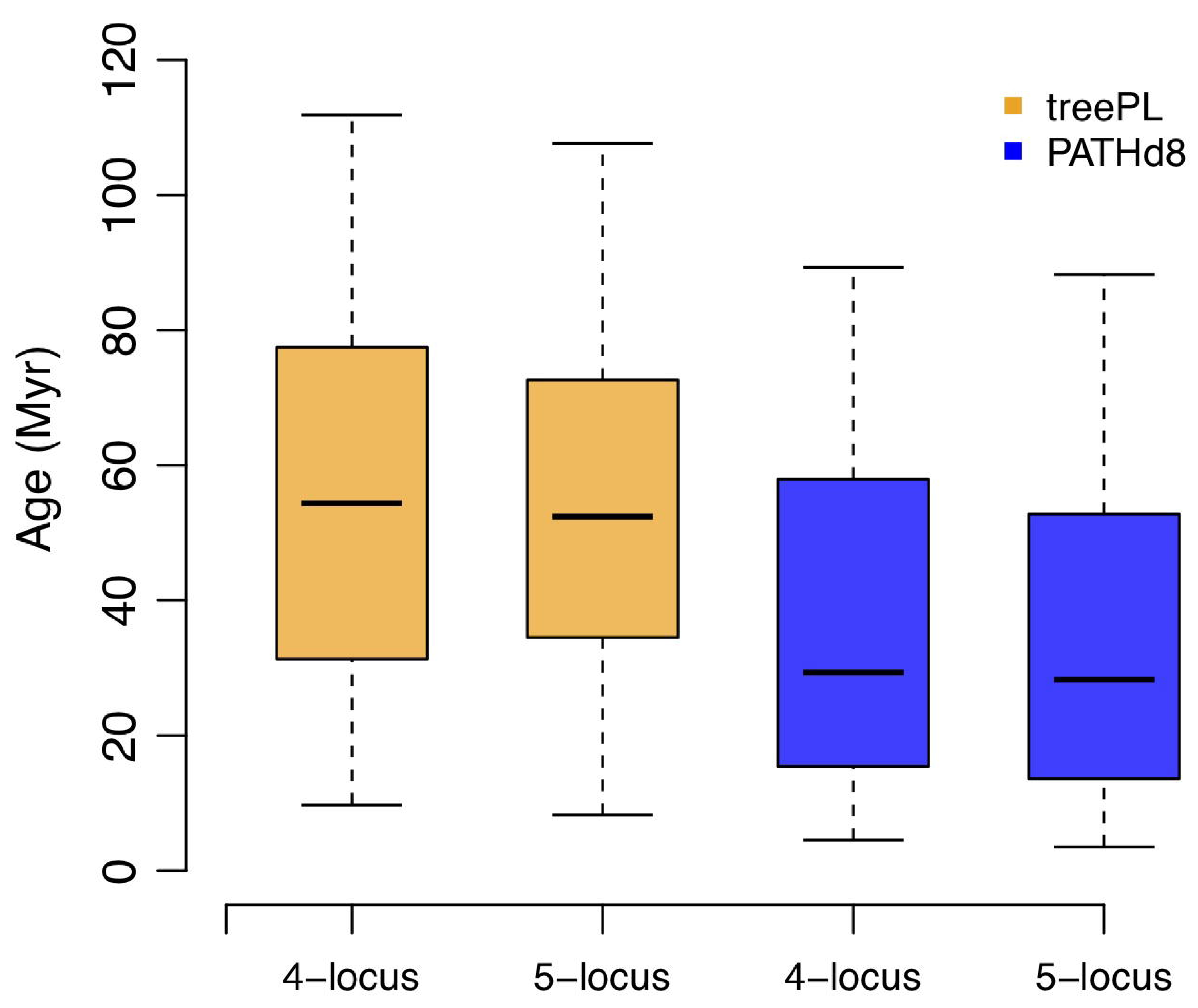




\section{Comparison of Crown Ages for Major Rosid Clades with Previous Studies}



